\title{
DETECTION OF THE GLASS TRANSITION OF POLYMERS USED IN ART AND ART-CONSERVATION USING RAMAN SPECTROSCOPY
}

\author{
Iacopo Osticioli, Andrea Azelio Mencaglia, Daniele Ciofini, Salvatore Siano \\ Istituto di Fisica Applicata "Nello Carrara" - Consiglio Nazionale delle Ricerche (IFAC-CNR), Florence, Italy \\ *i.osticioli@ifac.cnr.it
}

Keywords: Softening point, terpenoid resins, thermoplastic polymers, colophony, polystyrene

\begin{abstract}
In this work Raman spectroscopy was employed for the detection of the glass transition temperatures ( $\mathrm{Tg}$ ) of some thermoplastic polymers and natural terpenoid resins. In particular, our attention was focused on evaluating the $\mathrm{Tg}$ of polystyrene and colophony. The measurements returned $\mathrm{Tg}$ values in accordance with those reported in the literature obtained using the DSC technique, thus confirming the reliability of the approach proposed herein. Further studies will be focused on the evaluation of Tg temperature changes depending on materials treatments and ageing.
\end{abstract}

\section{Introduction}

Glass transition is a second order transition occurring at a characteristic temperature $(\mathrm{Tg})$, corresponding to the transformation of a solid (glassy) material to a softer state (rubbery) and vice versa. In amorphous materials this is the primary transition. Tg is a very important parameter to be considered in order to objectively evaluate the performance of a material because it primarily affects the chemical and physical properties such as heat capacity, linear coefficient of thermal expansion and elasticity [1]. Polymers have several different phases (glassy, LC, crystalline and isotropic). Glass transition in polymers has found great interest in the last years given that, under $\mathrm{Tg}$ conditions, they behave as a hard disordered solid with a microscopic glassy structure, while above they change considerably structure becoming rubberlike and comparatively softer, thus changing their physical properties over time [2]. The knowledge of $\mathrm{Tg}$ of polymers used in art and its conservation is important in order to achieve proper performance, especially when the material is intended for outdoor exposition. In this respect, polymers used in conservation generally have a $\mathrm{Tg}$ far enough away from the ambient temperature [3].

Besides, thermoplastic polymeric materials are widespread in modern art museum collections and they have been used extensively in the production of design objects [4]. Moreover, natural materials, such as dammar, mastic, sandarac, colophony, and shellac resins, commonly used in art, as well as in current conservation treatments, have been investigated.
In this work, Raman spectroscopy is proposed as an alternative technique to the most commonly used differential scanning calorimetry (DSC) and dilatometry techniques, for measuring $\mathrm{Tg}$ of thermoplastic polymers and natural resins used in art and conservation. Raman spectroscopy represents a non-invasive approach with a spatial resolution higher than DSC.

\section{Materials and methods}

A compact Raman device was assembled for the present purpose, using a spectrometer equipped with a deep-cooled ($60^{\circ} \mathrm{C}$ ) InGaAs array detector and a monochromator covering the spectral range between $165-1825 \mathrm{~cm}^{-1}$. The exciting source was a ultra-narrow linewidth diode pumped CW $\mathrm{Nd}$ :YAG (1064 nm) laser. Although at $1064 \mathrm{~nm}$ the absorption of the materials understudy is low, an automated control of the laser power and energy release was used in order to prevent any undesired overheating effect within the irradiated volume. This included a thermoelectric sensor providing the feedback signal for suitably modulating the output power of the laser source, according to a method reported elsewhere [5]

The detection of $\mathrm{Tg}$ has been achieved by monitoring the frequency shifts in the Raman bands with increasing temperature in a range between $25-170{ }^{\circ} \mathrm{C}$. Tg of commercial thermoplastic polymers such as Polyvinylacetate (PVAc), Polymethyl-methacrylate (PMMA), Polystyrene (PS) was measured. Besides, the Tg of natural materials, such as dammar, mastic, sandarac, colophony and shellac resins provided by Zecchi (Florence, Italy) and commonly used in art, was also detected. In order to have a homogeneous surface morphology for the analysis, the samples were prepared by heating pure synthetic and natural polymers products up to their melting point and then let them cool at environmental temperature. The determination of the frequency shift was achieved through the weighted average of specific Raman bands of the spectra, $\bar{v}$, on the basis of the equation:

$\overline{\mathrm{v}}=\frac{\sum_{i=1}^{n}\left(I_{i} \cdot \tilde{\mathrm{v}}_{i}\right)}{\sum_{i=1}^{n} I_{i}}$

where $I_{i}$ is the Raman intensity in an interval of wavenumbers $\left(\tilde{v}_{i}\right)$ within the peak's range. This approach provides a sort of "centre of mass" of the selected Raman band, which provided 
more repeatable and then reliable determinations of the band centre with respect to the usual peak fitting approach.

\section{Results}

Raman measurements were carried out on the abovementioned thermoplastic polymers as well as natural resins. Two examples for each category are herein discussed. Figure 1a shows Raman spectra of polystyrene as acquired at different temperatures ranging from 24 to $168^{\circ} \mathrm{C}$.
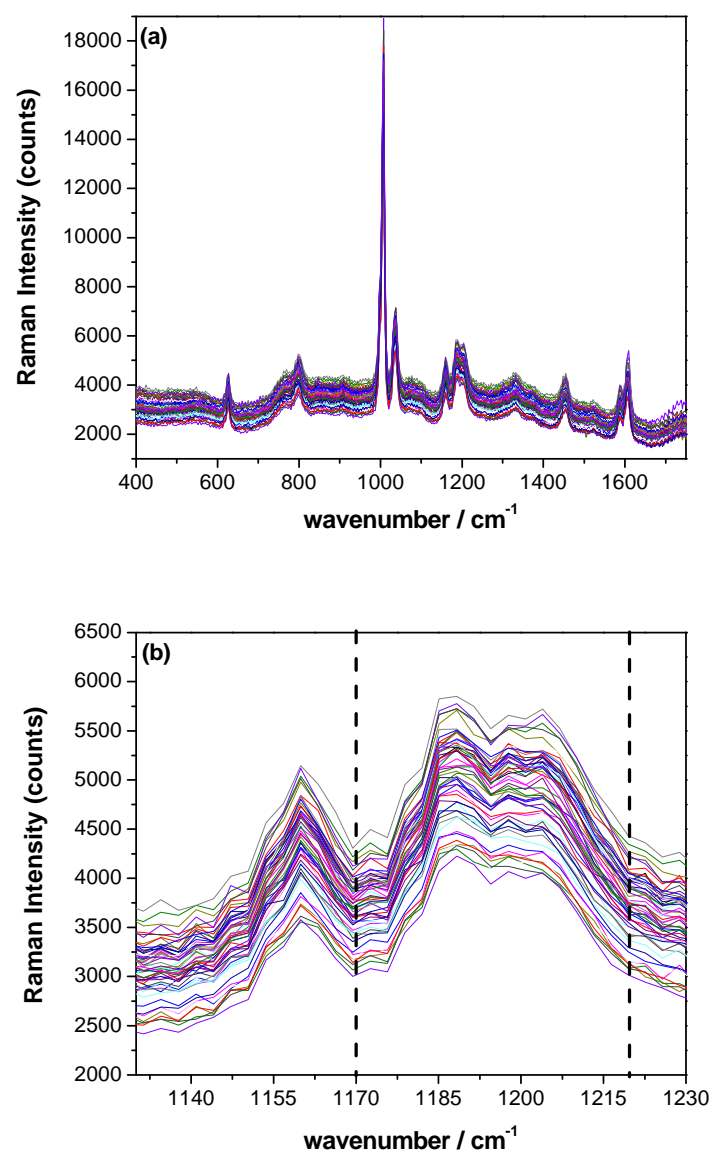

Fig. 1 Overview of the Raman spectra of polystyrene at different temperatures ranging between $24-168{ }^{\circ} \mathrm{C}$ : (a) whole fingerprint spectral region; (b) zoomed view of the spectral region used for deriving $\mathrm{Tg}\left(1170-1220 \mathrm{~cm}^{-1}\right)$.

Table 1: polystyrene vibrational modes assignment

\begin{tabular}{ll}
\hline $\begin{array}{l}\text { Raman Frequency } \\
\left(\mathrm{cm}^{-1}\right)\end{array}$ & Vibrational assignment \\
\hline 623 & Aromatic ring deformation \\
765 & $\mathrm{C}-\mathrm{H}$ out of plane, $\rho(\mathrm{C}-\mathrm{H})$ \\
1007 & $\rho(\mathrm{C}-\mathrm{C})$ \\
1033 & $v(\mathrm{H}-\mathrm{C}-\mathrm{H})$ \\
1159 & $\delta(\mathrm{C}-\mathrm{C})$ \\
1188 & $v(\mathrm{C}-\mathrm{C}), \delta(\mathrm{H}-\mathrm{C}-\mathrm{H})$ \\
1200 & $\delta(\mathrm{C}-\mathrm{C}-\mathrm{H}), v(\mathrm{C}-\mathrm{C})$ \\
1329 & $\rho(\mathrm{H}-\mathrm{C}-\mathrm{H}), \delta(\mathrm{C}-\mathrm{C}-\mathrm{H})$ \\
1454 & $\delta(\mathrm{H}-\mathrm{C}-\mathrm{H}$ \\
\hline
\end{tabular}

\begin{tabular}{ll}
\hline 1590 & $v(\mathrm{C}-\mathrm{C}), \delta(\mathrm{C}-\mathrm{C}-\mathrm{H})$ \\
1606 & $v(\mathrm{C}-\mathrm{C}), \delta(\mathrm{C}-\mathrm{C}-\mathrm{H})$ \\
\hline
\end{tabular}

Vibrational modes assignments of polystyrene Raman bands shown in Fig- 1 are listed in Tab. 1 in accordance with the literature $[6,7]$

In particular, the spectral region between $1170-1220 \mathrm{~cm}^{-1}$ was selected for monitoring frequency shifts with temperature according to Liem et al. [2]. Weighted averages (Eq. 1) were calculated for both the bands at 1188 and $1200 \mathrm{~cm}^{-1}$ in order to detect any minimal change in the molecular structure. Figure $1 \mathrm{~b}$ shows a detail of the spectral region of interest: black dashed lines indicate the extremes of the interval for calculating weighted average.

Figure 2 shows weighted average values calculated from 1170 to $1220 \mathrm{~cm}^{-1}$ for each Raman spectrum of polystyrene as a function of temperature. A slope change is clearly observable around $110^{\circ} \mathrm{C}$. This is the first time that glass transition is achieved by means of weighted average calculations on Raman spectroscopic data. For this reason, in accordance with what stated by Rieger [6] regarding the analysis of DSC curves, the onset glass transition temperature $\left(\mathrm{Tg}_{0}\right)$ was defined as the intersection of the two lines obtained by fitting the two point-clouds with different slopes. The intersection of the two red lines shown in Fig. 2 therefore provided a $\mathrm{Tg}_{0} \cong 96^{\circ} \mathrm{C}$, in good agreement with the corresponding value reported in the literature $[2,8]$. The parameters of the mentioned linear fittings are reported in Tab. 2 .

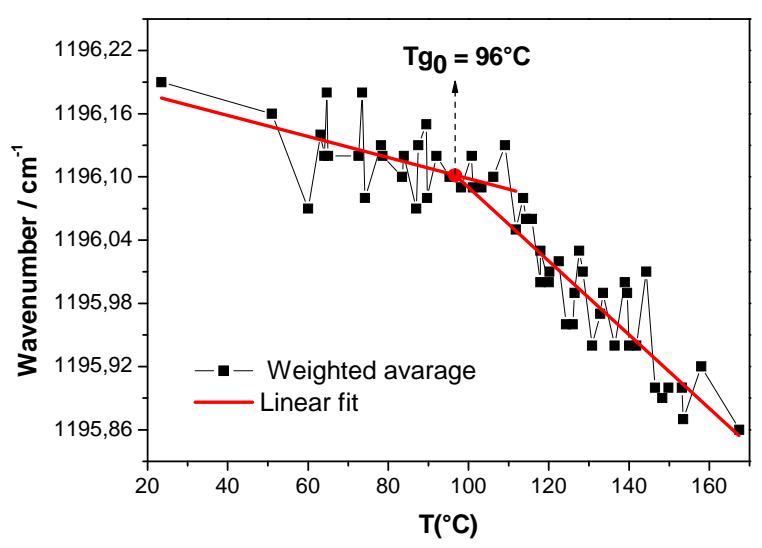

Fig. 2 Weighted averages of the peak position between 1170$1220 \mathrm{~cm}^{-1}$ of polystyrene as a function of temperature and associated linear fittings.

Table 2: linear fit parameters

\begin{tabular}{lll}
\hline & Value & Error \\
\hline Intercept $1\left(\mathrm{~cm}^{-1}\right)$ & 1196.20 & 0.02 \\
Slope 1 $\left(\mathrm{cm}^{-1} /{ }^{\circ} \mathrm{C}\right)$ & -0.0010 & $310^{-4}$ \\
Intercept $2\left(\mathrm{~cm}^{-1}\right)$ & 1196.44 & 0.05 \\
Slope 2 $\left(\mathrm{cm}^{-1} /{ }^{\circ} \mathrm{C}\right)$ & -0.0035 & $410^{-4}$ \\
\hline
\end{tabular}


It is worth noting that the application of weighted average data allows detecting molecular changes resulting in very small frequency shifts (on the order of $1 \mathrm{~cm}^{-1}$ ).

The frequency shift is due to the change of the relative amount of glassy and crystalline components of the material with the temperature [1]. Besides, at Tg, Raman modes are also affected by the discontinuity in the thermal expansion and other physical properties, which are directly correlated to intermolecular interactions.

Also natural resins underwent glass transitions and the value of $\mathrm{T}_{\mathrm{g}}$ was determined in a similar way as for polystyrene.
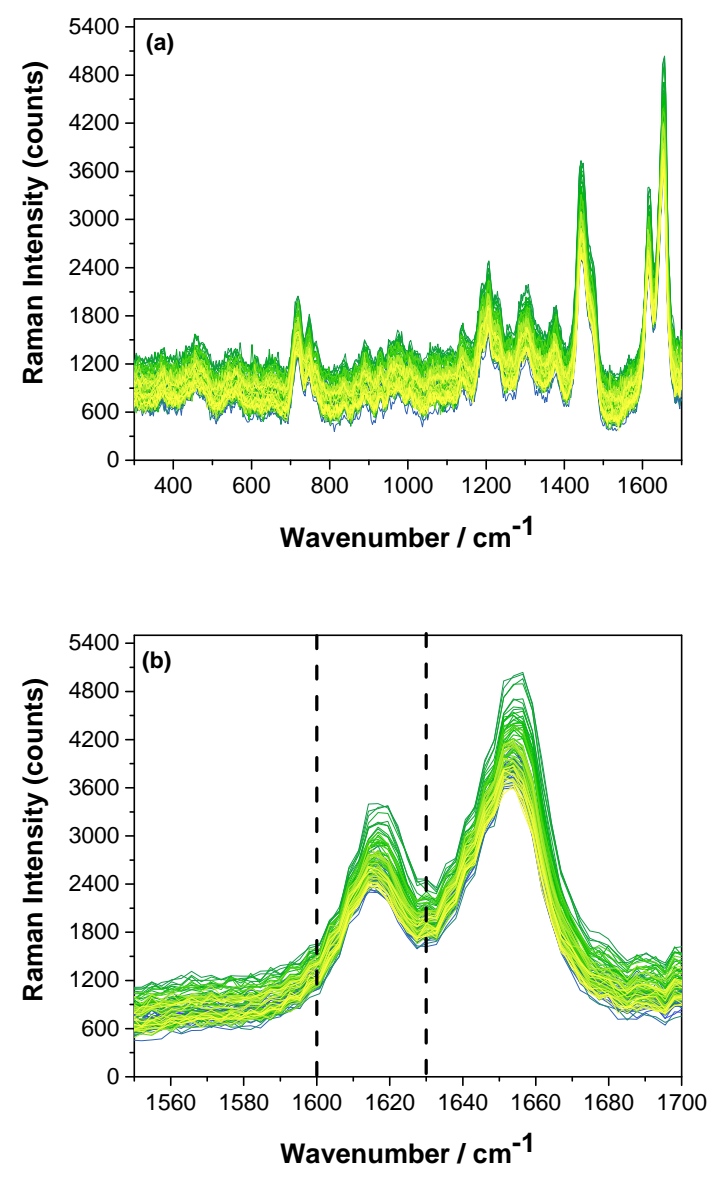

Fig. 3 Overview of the Raman spectra of colophony at different temperatures ranging from 24 to $127^{\circ} \mathrm{C}$ : (a) whole fingerprint spectral region; (b) zoomed view of the spectral region used for deriving $\mathrm{Tg}\left(1600-1630 \mathrm{~cm}^{-1}\right)$.

As an example, Fig. 3a displays Raman spectra of colophony acquired at different temperatures $\left(24-127^{\circ} \mathrm{C}\right)$. In particular, the spectral region between $1600-1630 \mathrm{~cm}^{-1}$ was selected for monitoring frequency shifts with temperature (Fig. 3b).

Vibrational modes assignments of Raman bands of colophony shown in Fig. 3 are listed in table 3 in accordance with the literature [9].
Table 3: colophony vibrational modes assignment

\begin{tabular}{ll}
\hline $\begin{array}{l}\text { Raman Frequency } \\
\left(\mathrm{cm}^{-1}\right)\end{array}$ & Vibrational assignment \\
\hline $710-750$ & $v(\mathrm{C}-\mathrm{C})$ \\
885 & $v(\mathrm{C}-\mathrm{C})$ \\
974 & $\rho(\mathrm{CH})$ \\
1138 & $v(\mathrm{C}-\mathrm{C}), v(\mathrm{COC})$ \\
1207 & $\delta(\mathrm{H}-\mathrm{C}=\mathrm{C}-\mathrm{H})$ \\
1293 & $\tau(\mathrm{H}-\mathrm{C}-\mathrm{H})$ \\
1379 & $\delta(\mathrm{H}-\mathrm{C}-\mathrm{H}), \delta\left(\mathrm{CH}_{3}\right)$ \\
1449 & $\delta(\mathrm{H}-\mathrm{C}-\mathrm{H}), \delta\left(\mathrm{CH}_{3}\right)$ \\
1620 & $v(\mathrm{C}=\mathrm{C})$ \\
1657 & $v(\mathrm{C}=\mathrm{C})$ \\
\hline
\end{tabular}

Figure 4 reports the weighted averages of the peak position between $1600-1630 \mathrm{~cm}^{-1}$ of colophony as a function of temperature. In order to evaluate the data-set reproducibility, five Raman spectra for each temperature value were acquired. As in polystyrene, the intersection between the two linear fittings the scatter plot led to $\mathrm{Tg}_{0} \cong 53{ }^{\circ} \mathrm{C}$, in agreement with the range of temperatures reported in the literature for terpenoid resins [2]. In fact, it is known that glass transition of these materials undergoes significant changes and it strongly depends on the composition and degree of purity, which can vary depending on provenance, harvesting conditions, processing, and subsequent storage of the raw material. Besides, when applied as protective coatings, ageing, pollution, and many other causes affect their physical and chemical properties. Linear fit parameters are reported in Tab. 4.

Table 4: linear fit parameters

\begin{tabular}{lll}
\hline & Value & Error \\
\hline Intercept $1\left(\mathrm{~cm}^{-1}\right)$ & 1614.20 & 0.03 \\
Slope $1\left(\mathrm{~cm}^{-1} /{ }^{\circ} \mathrm{C}\right)$ & -0.0010 & $710^{-4}$ \\
Intercept $2\left(\mathrm{~cm}^{-1}\right)$ & 1614.51 & 0.04 \\
Slope 2 $\left(\mathrm{cm}^{-1} /{ }^{\circ} \mathrm{C}\right)$ & -0.0068 & $410^{-4}$ \\
\hline
\end{tabular}

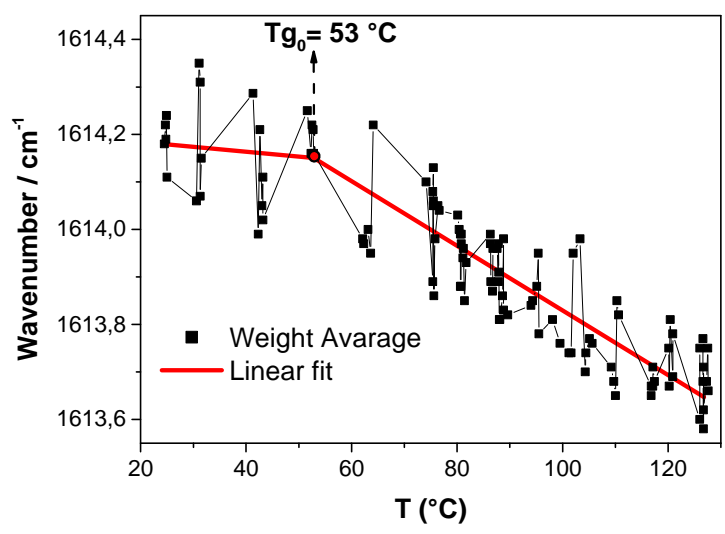

Fig. 4 Weighted average of the peak position of colophony between 1600-1630 $\mathrm{cm}^{-1}$ as a function of temperature and associated linear fittings. 


\section{Conclusions}

Glass transition temperatures of polystyrene and colophony were successfully detected through Raman spectroscopy measurements. The Tg values determined were in accordance to those detected using DSC. The possibility of measuring Tg using a non-invasive portable technique allowing for spatial resolution appears of particular interest in order to assess the state of conservation of polymeric artifacts. Furthermore, the present approach might be also of interest for optimizing and assessing laser conservation treatments, which involve photothermal processes. In particular, the Raman technique could provide direct information on the energy coupling to the material layers to be safeguarded and then on the overall selectivity of the laser irradiation treatment.

Further studies will be focused on the evaluation of $\mathrm{Tg}$ changes associated with ageing and conservation treatments of various artifacts of cultural interest.

\section{Acknowledgements}

The present study was carried out in the framework of the European Project IPERION CH - Integrated Platform for the European Research Infrastructure on Cultural Heritage (H2020-INFRAIA-2014-2015, Grant Agreement n. 654028).

\section{References}

[1] Samith V. D., Ramos-Moore E., Study of glass transition in functionalized poly(itaconate)s by differential scanning calorimetry, Raman spectroscopy and thermogravimetric analysis, J. Non-Cryst. Solids, 2015, 408, pp. 37-42

[2] Liem H., Cabanillas-Gonzalez J., Etchegoi P., Bradley D. D. C., Glass transition temperatures of polymer thin films monitored by Raman scattering, J. Phys.: Condens. Matter, 2004, 16, pp. 721-728

[3]Schilling M. R., The Glass Transition of Materials Used in Conservation, Stud. in Conserv., 1989, 34 (3), pp. 110-116

[4] Toja F., Nevin A., Comelli D., Levi M., Cubeddu R., Toniolo L., Fluorescence and Fourier-transform infrared spectroscopy for the analysis of iconic Italian design lamps made of polymeric materials, Anal. Bioanal. Chem, 2011, 399 (9), pp. 2977-2986

[5] Osticioli I. Mencaglia A.A., Siano S., Temperaturecontrolled portable Raman spectroscopy of photothermally sensitive pigments, Sensor Actuat. B-Chem 2017, 238, pp. $772-778$

[6] Rieger J., The Glass Transition Temperature Of Polystyrene: Results of a round robin test, J. Ther. Anal., 1996, 46, pp. 965-972.

[7] Botelho do Rego A. M, Rei Vilar M., Lopes da Silva J., Mechanisms of vibrational and electronic excitation of polystyrene filma in high resolution electron loss energy spectroscopy, J. Electron Spectrosc., 1997, 85, pp. 81-91

[8] Torres F. J., Civalleri B., Meyer A., Musto P., Albunia A. R., Rizzo P., Guerra G., Normal Vibrational Analysis of the Syndiotactic Polystyrene s(2/1)2 Helix, J. Phys. Chem. B, 2009, 113, pp. 5059-5071
[9] Osticioli I., Ciofini D., Mencaglia A. A., Siano S., , Automated characterization of varnishes photo-degradation using portable T-controlled Raman spectroscopy, Spectrochim. Acta A. DOI: 10.1016/j.saa.2016.03.016. 